\title{
Prevalence of chronic pain in the elderly Polish population - results of the PolSenior study
}

Elzbieta Kozak-Szkopek ${ }^{1}$, Katarzyna Broczek ${ }^{1}$, Przemyslaw Slusarczyk², Katarzyna Wieczorowska-Tobis ${ }^{3}$, Alicja Klich-Raczka4 , Aleksandra Szybalska², Malgorzata Mossakowska²

\begin{abstract}
${ }^{1}$ Department of Geriatrics, Medical University of Warsaw, Warsaw, Poland ${ }^{2}$ International Institute of Molecular and Cell Biology, Warsaw, Poland ${ }^{3}$ Department of Palliative Care, Poznan University of Medical Sciences, Poznan, Poland ${ }^{4}$ Department of Internal Medicine and Gerontology, Jagiellonian University Medical College, Krakow, Poland
\end{abstract}

Submitted: 20 February 2015

Accepted: 5 July 2015

Arch Med Sci 2017; 13, 5: 1197-1206

DOI: 10.5114 /aoms.2015.55270

Copyright (C 2016 Termedia \& Banach

\section{Abstract}

Introduction: Pain is the most common complaint of elderly people. In Poland, no large studies on the prevalence of chronic pain in the elderly were conducted until recently.

Material and methods: The study was a part of the PolSenior project, a cross-sectional multidisciplinary study on ageing of the Polish population, and included a randomly selected group of 716 people aged 55-59 years, and 4979 people over 65 years. The survey was conducted through a standardized questionnaire. An evaluation of pain occurrence, location, intensity and coexistence of pains in relation to gender, age and use of health care was performed.

Results: Chronic pain affected $42.0 \%$ of respondents aged 65 years and over ( $48.6 \%$ of women and $35.8 \%$ of men) as compared to $35.2 \%$ of the pre-elderly. The most common pain locations were the lumbar region (51.6\%) and knees (41.0\%). The average number of pain sites was $3.1 \pm 2.3$. Average intensity of pain was 6.2 points on the VAS scale in people over 65 years and 6.0 points in the pre-elderly (NS). Average pain intensity increased significantly from 5.7 points in patients reporting pain in one place to 7.2 points in those reporting six pain sites. Elderly respondents with pain compared to those without pain more frequently reported physician visits performed at least once a month $(54.6 \%$ vs. $48.4 \%, p<0.001)$.

Conclusions: Polish elderly most frequently complained of low back and lower limb pain. In respondents reporting many sites of pain, an increase in the intensity of pain was observed. Elderly patients with chronic pain often use medical care.

Key words: chronic pain, elderly population, PolSenior study, representative survey, advanced age.

\section{Introduction}

Old age is characterized by the coexistence of health problems resulting from the aging process and the presence of many chronic diseases affecting individual systems and organs. In elderly people, the most frequent diseases are cardiovascular system diseases, but the most common complaints are of pain. Changes associated with aging and diseases of the musculoskeletal and nervous systems lead to increased incidence of pain with age. The number of people with chronic pain will continue

\author{
Corresponding author: \\ Elzbieta Kozak-Szkopek PhD \\ Department of Geriatrics \\ Medical University of Warsaw \\ 4 Oczki St \\ 02-007 Warsaw, Poland \\ Phone: +48 226229682 \\ E-mail: elzbieta.kozak- \\ szkopek@wum.edu.pl
}


to rise due to the lengthening of life expectancy and an increase in the proportion of older people in society [1].

The problem of chronic pain in the elderly is underestimated. Reported pain is often underestimated by both caregivers and physicians, and is perceived as belonging to the image of old age. The perception of chronic pain causes mood disorders, leading to a reduction of life activity [2, 3]. Chronic pain especially in the elderly is a risk factor for worsening mobility, increasing the risk of falls and their consequences [4]. Experiencing chronic pain worsens the patient's functional abilities and contributes to dependence on caregivers $[5,6]$. The occurrence of chronic pain results in the overuse of analgesics and increases the frequency of health care utilization [7-9]. It can also significantly impair the quality of life of older people $[10,11]$.

Research on the prevalence of chronic pain typically involves the adult population [12]. In a pan-European study involving people over 18 years of age from 15 European countries and Israel, the prevalence of chronic pain ranged from $12 \%$ to $30 \%$ of respondents, and was the highest in Norway (30\%), Poland (27\%), and Italy (26\%), and the lowest in Spain (12\%) and the UK (13\%) [13]. A report published in 2011, assessing the prevalence of pain in the European Union, based on data from an online database of the population of the UK, France, Spain, Germany and Italy, showed that one in five adult Europeans suffers from pain [14].

The prevalence of pain in the elderly has been evaluated in several European countries, Asia and the Americas. The results of these studies indicate a wide variation of pain occurrence, ranging from $25.2 \%$ in the Australian elderly population [15], through nearly $40 \%$ in the population of Spain [16] and the United States [17], to over $80 \%$ of seniors in the population of Brazil [18].

In Poland, no extensive studies on the prevalence and characteristics of chronic pain in the elderly have been conducted until recently.

The aim of the study was to assess the prevalence of chronic pain in the Polish elderly population and to characterize pains in terms of their occurrence, location, intensity, and depending on the age and sex of the respondents.

\section{Material and methods}

The study was conducted in 5695 respondents, including 716 people aged 55-59 years and in 4979 people over the age of 65 years who participated in the PolSenior study, the largest ever cross-sectional multidisciplinary study of the elderly population in Poland. The study group was randomly selected from the population of Poles by a three-step schema (step 1 - municipality, step 2
- a village in the rural areas or street in urban areas, step 3 - an address from the Universal Electronic System for Registration of the Population) to ensure representativeness of the sample. Groups by age included one cohort of pre-elderly adults (55-59 years) and six age cohorts of elderly people $(65-69,70-74,75-79,80-84,85-89$ and 90 and over). An equal number of respondents in designated age groups and an equal number of men and women in each age range were assumed. The PolSenior project methodology has been described in detail elsewhere [19].

The fieldwork was conducted from July 2008 to May 2010 by using a standardized questionnaire, filled out by a trained nurse during two visits to the respondent's place of residence.

Respondents answered the following questions about pain:

- Have you felt a nagging pain for longer than three months?

- Where it is localized (head, shoulder, neck, upper back, low back, hand, hip, knee, foot, leg, other location)? Respondents had the possibility of identifying multiple sites of pain.

- Which of these places is the most painful? It was necessary to identify one of these places.

Answers on pain perception were obtained from 2875 out of 2899 male respondents (99.2\% response rate) and from 2776 out of 2796 female respondents ( $99.3 \%$ response rate).

Respondents who answered affirmatively to the question about the perception of pain were asked to rate the pain intensity on a scale of 0 to 10 , where 0 is no pain and 10 is the greatest pain imaginable (Visual Analog Scale - VAS). The assessment of pain intensity was related to the currently most painful place. Data on pain intensity were obtained from 1097 out of 1162 women (94.4\%) and 863 out of 911 men (94.7\%) aged 65 years or more and from 140 out of 141 women (99.3\%) and 109 out of 110 men (99.1\%) aged 55-59 years.

Respondents were also asked how often they usually contacted their family doctor. The answer was obtained from $82.2 \%$ of respondents who answered the question about pain. This relatively low percentage was probably due to the fact that the question was placed in a section of the questionnaire performed during the second visit to the respondent, which did not always occur.

The study design with the number of participants and missing data is presented in Figure 1. An evaluation of all data acquired from respondents including pain occurrence, pain location, the coexistence of different sites of pain and pain intensity in relation to gender, age and the use of health care was performed.

The PolSenior project was approved by the Bioethics Commission of the Medical University of 


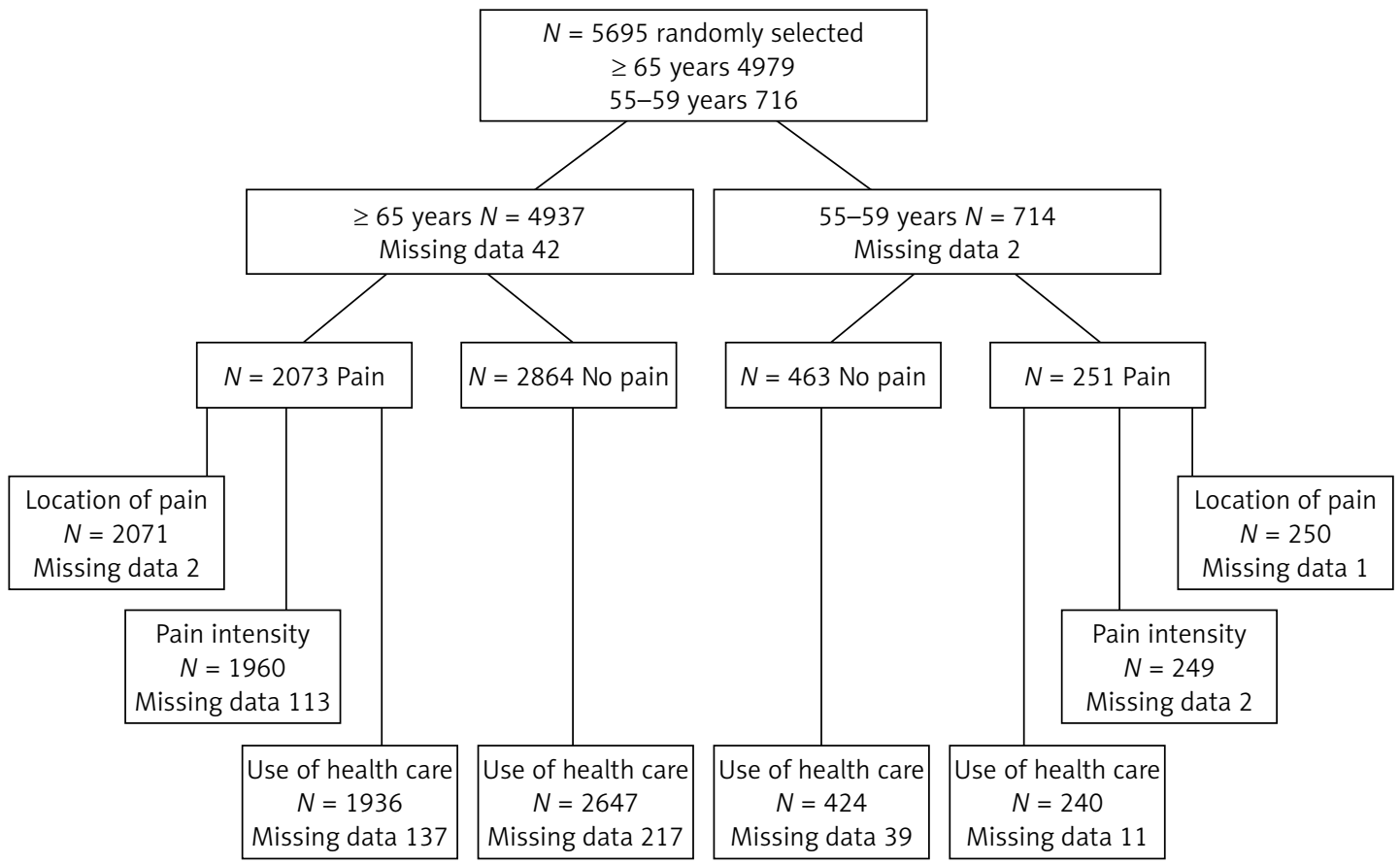

Figure 1. Characteristics of study groups

Silesia, Katowice. Each respondent or their caregiver signed an informed consent form.

A detailed analysis of such questions as prevalence of pain in correlation with socio-economic factors (marital status, education, occupation, place of living), functional performance, cognitive status and comorbidities was not addressed in this work and will be included in future publications.

\section{Statistical analysis}

The results were statistically analyzed using StatSoft Statistica. The significance of differences in mean values was tested using ANOVA. To analyze the prevalence of pain the $\chi^{2}$ test was used, and, for age groups, the Cochran-Armitage test for trend was applied. Because of the pairwise deletion of missing values, each analysis took into account a slightly different number of observations. To calculate the dissemination of pain in the whole group, statistical weights for reproducing the structure of the elderly population in Poland were used.

\section{Results}

\section{Prevalence of chronic pain}

The incidence of pain in the surveyed women and men of the PolSenior population in each age group is shown in Table I. Significantly more subjects aged 65 and older reported experiencing chronic pain, compared with those aged 55-59

Table I. Prevalence of chronic pain in women and men in different age groups of the PolSenior population

\begin{tabular}{|c|c|c|c|c|c|c|c|c|c|c|}
\hline \multirow{2}{*}{$\begin{array}{l}\text { Age group } \\
\text { [years] }\end{array}$} & \multirow{2}{*}{$\begin{array}{c}N^{\mathrm{a}} \\
(100 \%)\end{array}$} & \multicolumn{2}{|c|}{ Total } & \multirow{2}{*}{$\begin{array}{c}N^{\mathrm{a}} \\
(100 \%)\end{array}$} & \multicolumn{2}{|c|}{ Men } & \multirow{2}{*}{$\begin{array}{c}N^{\mathrm{a}} \\
(100 \%)\end{array}$} & \multicolumn{2}{|c|}{ Women } & \multirow[t]{2}{*}{$P$-value } \\
\hline & & $n^{\mathrm{b}}$ & $\%$ & & $n^{\mathrm{b}}$ & $\%$ & & $n^{\mathrm{b}}$ & $\%$ & \\
\hline $55-59$ & 714 & 251 & 35.2 & 331 & 110 & 33.2 & 383 & 141 & 36.8 & NS \\
\hline $65+$ & 4937 & 2073 & 42.0 & 2544 & 911 & 35.8 & 2393 & 1162 & 48.6 & $<0.001$ \\
\hline $65-69$ & 778 & 328 & 42.2 & 373 & 146 & 39.1 & 405 & 182 & 44.9 & NS \\
\hline $70-74$ & 920 & 390 & 42.4 & 480 & 170 & 35.4 & 440 & 220 & 50.0 & $<0.001$ \\
\hline $75-79$ & 840 & 352 & 41.9 & 440 & 155 & 35.2 & 400 & 197 & 49.3 & $<0.001$ \\
\hline $80-84$ & 785 & 347 & 44.2 & 417 & 155 & 37.2 & 368 & 192 & 52.2 & $<0.001$ \\
\hline $85-89$ & 854 & 372 & 43.6 & 462 & 171 & 37.0 & 392 & 201 & 51.3 & $<0.001$ \\
\hline 90 and over & 760 & 284 & 37.4 & 372 & 114 & 30.7 & 388 & 170 & 43.8 & $<0.001$ \\
\hline
\end{tabular}

$N^{a}-$ number of participants, $n^{b}-$ number of participants with chronic pain. 
years $(42.0 \%$ vs. $35.2 \%, p<0.001)$. Elderly women were significantly more likely to report pain compared to men in each age group. The highest percentage of people reporting pain was found among women aged $80-84$ years $(52.2 \%)$ and among men aged 65-69 years (39.1\%), and the lowest in the group of women and men aged 90 years and more (43.8\% and $30.7 \%$, respectively).

After applying statistical weights to the data, it was calculated that in the Polish population of people aged 65 and over, chronic pain affects $43.8 \%$ of people $-48.2 \%$ of women and $36.5 \%$ of men.

\section{Location of pain}

The most common location of pain among respondents with pain aged 65 years and more, both women and men, was the lumbar region (low back pain) (51.6\%), and the least frequently reported was hand pain (17.2\%) (Table II).

The prevalence of pain in relation to particular locations in subjects with pain in the age groups is presented in Table III. In the group of people between 65 and 79 years of age, the most prevalent was low back pain (55.9\%), followed by legs (42.0\%), knees (40.5\%) and hips (29.2\%), while in the group of over 80 -year-olds the most common location was the legs (52.6\%), followed by the lumbar area (47.1\%) and knees (41.6\%). Interestingly, the incidence of low back pain was highest in pre-elderly people (60.0\%) and decreased in subsequent age groups to $44.4 \%$ in those over 90 years old ( $p<0.001, \chi^{2}$ test for trend). In contrast, the incidence of leg pain was lowest in people aged 55-59 years (39.2\%) and increased with age from $40.9 \%$ in the group of 65 -69-year-olds to over $50 \%$ in people over 85 years $\left(p<0.001, \chi^{2}\right.$ test for trend).

Pains in the hips and knees were nearly twice as common in women as in men (hips: $33.3 \%$ vs. $21.7 \%$, knees: $49.9 \%$ vs. $29.7 \%$, respectively). Knee pain was mostly reported by women aged 70-84 years, and men aged 65-69 years and those over 80 years.

Headaches were not significantly more frequent in people aged 55-59 years compared with those aged more than 65 years $(27.6 \%$ vs. $23.8 \%$, NS). However, among people over 65 years the incidence of headaches remained at a similar level in subsequent age groups (20.1-24.5\%) and grew rapidly in people over 90 years old $(35.9 \%, p<$ $0.001, \chi^{2}$ test for trend).

After applying statistical weights to forecast the data from the PolSenior population to the entire elderly Polish population, the lumbar region remained the most common site of pain $(55.4 \%)$, followed by the knees (44.4\%), legs (43.7\%), hips (31.2\%), upper back (26.5\%), shoulder (24.9\%) and head (21.6\%).

\section{Co-occurrence of pain in multiple locations}

In the study population of over 65-year-olds with pain, $1456(70.3 \%)$ reported pain in at least two places, $993(47.9 \%)$ in at least three places, 683 (33.0\%) in at least four places, $467(22.5 \%)$ in at least five places, 316 (15.3\%) in at least six places, and $200(9.7 \%)$ patients in at least seven places. No differences were observed in the coexistence of pain in multiple locations (at least two sites of pain) in people aged 65 years and more, compared

Table II. Location of pain in people with chronic pain aged 65 and more of the PolSenior population

\begin{tabular}{|c|c|c|c|c|c|c|c|c|c|c|}
\hline \multirow{2}{*}{$\begin{array}{l}\text { Pain locations } \\
65+\end{array}$} & \multirow{2}{*}{$\begin{array}{c}N^{\mathrm{a}} \\
(100 \%)\end{array}$} & \multicolumn{2}{|c|}{ Total } & \multirow{2}{*}{$\begin{array}{c}N^{\mathrm{a}} \\
(100 \%)\end{array}$} & \multicolumn{2}{|c|}{ Men } & \multirow{2}{*}{$\begin{array}{c}N^{\mathrm{a}} \\
(100 \%)\end{array}$} & \multicolumn{2}{|c|}{ Women } & \multirow[t]{2}{*}{$P$-value } \\
\hline & & $n^{\mathrm{b}}$ & $\%$ & & $n^{\mathrm{b}}$ & $\%$ & & $n^{b}$ & $\%$ & \\
\hline Head & 2071 & 492 & 23.8 & 909 & 177 & 19.5 & 1162 & 315 & 27.1 & $<0.001$ \\
\hline Shoulder & & 471 & 22.7 & & 171 & 18.8 & & 300 & 25.8 & $<0.001$ \\
\hline Neck & & 434 & 21.0 & & 152 & 16.7 & & 282 & 24.3 & $<0.001$ \\
\hline Upper back & & 544 & 26.3 & & 197 & 21.7 & & 347 & 29.9 & $<0.001$ \\
\hline Lower back & & 1069 & 51.6 & & 412 & 45.3 & & 657 & 56.5 & $<0.001$ \\
\hline Hand & & 356 & 17.2 & & 110 & 12.1 & & 246 & 21.2 & $<0.001$ \\
\hline Hip & & 584 & 28.2 & & 197 & 21.7 & & 387 & 33.3 & $<0.001$ \\
\hline Knee & & 850 & 41.0 & & 270 & 29.7 & & 580 & 49.9 & $<0.001$ \\
\hline Foot & & 434 & 21.0 & & 161 & 17.7 & & 273 & 23.5 & 0.001 \\
\hline Leg & & 977 & 47.2 & & 403 & 44.3 & & 574 & 49.4 & 0.022 \\
\hline Others & & 229 & 11.1 & & 95 & 10.5 & & 134 & 11.5 & NS \\
\hline
\end{tabular}

$N^{a}$ - number of participants who reported chronic pain and pain locations, $n^{b}$-number of participants who reported chronic pain in specified locations. 


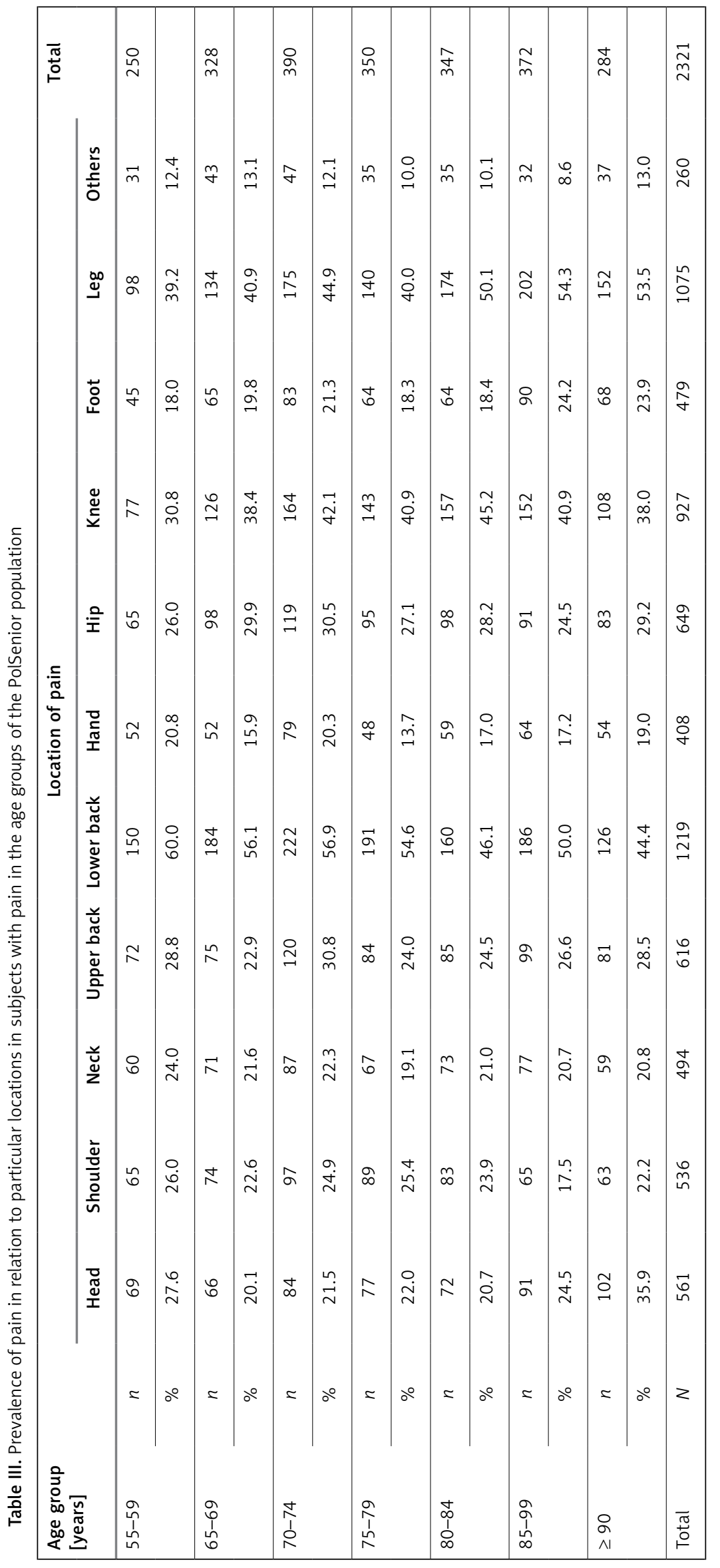


Table IV. Number of pain sites in subjects with chronic pain in the PolSenior population

\begin{tabular}{|c|c|c|c|c|c|c|c|}
\hline \multirow{2}{*}{$\begin{array}{l}\text { Age group } \\
\text { [years] }\end{array}$} & \multicolumn{2}{|c|}{ Total } & \multicolumn{2}{|c|}{ Men } & \multicolumn{2}{|c|}{ Women } & \multirow[t]{2}{*}{$P$-value } \\
\hline & Mean & $\pm S D^{a}$ & Mean & $\pm S D^{a}$ & Mean & $\pm S D^{a}$ & \\
\hline $55-59$ & 3.1 & 2.4 & 2.7 & 2.1 & 3.5 & 2.6 & 0.016 \\
\hline $65+$ & 3.1 & 2.3 & 2.6 & 1.9 & 3.5 & 2.4 & $<0.001$ \\
\hline $65-69$ & 3.0 & 2.1 & 2.5 & 1.9 & 3.4 & 2.2 & $<0.001$ \\
\hline 70-74 & 3.3 & 2.4 & 2.6 & 1.9 & 3.8 & 2.5 & $<0.001$ \\
\hline $75-79$ & 3.0 & 2.1 & 2.4 & 1.7 & 3.4 & 2.2 & $<0.001$ \\
\hline $80-84$ & 3.1 & 2.2 & 2.8 & 2.0 & 3.3 & 2.3 & 0.019 \\
\hline $85-89$ & 3.1 & 2.2 & 2.4 & 1.7 & 3.7 & 2.5 & $<0.001$ \\
\hline 90 and over & 3.3 & 2.6 & 2.9 & 2.2 & 3.5 & 2.8 & NS \\
\hline
\end{tabular}

$S D^{a}$ - standard deviation.

with the pre-elderly (70.3\% vs. $66.8 \%$, NS). Among respondents aged over 65 years co-occurrence of pain in different locations was significantly more frequently reported by women than by men $(76.7 \%$ vs. $62.2 \%, p<0.005)$. The average number of reported sites of pain among women compared to men in each age group was significantly higher and did not change with age (Table IV).

Participants of the PolSenior study reported an average of 3.1 locations of chronic pain. The average number of painful places calculated after applying the sample weighting for the entire population of Polish people aged 65 and more is 3.2 \pm 2.3 (median 2; 95\% confidence interval for the mean: 3.1-3.3).

\section{Intensity of pain}

Table $V$ shows the mean pain severity in subjects with chronic pain. The average intensity of pain was 6.2 points on the VAS scale in patients over 65 years and 6.0 points in those aged $55-59$ years (NS). The intensity of pain in people over 65 years was significantly higher in women than in men (6.5 points vs. 5.9 points, $p<0.001$ ). Women felt significantly stronger pain than men in the 5 -year age cohorts of 70 to 89 years of age, while in the younger age groups and among people over 90 years, there was no difference between the sexes. The intensity of pain in subsequent age cohorts of people over 65 years of age, men as well as women, did not change significantly.

Mild pain (1-4 points on the VAS scale) was felt by $20.3 \%$ of all respondents $(16.9 \%$ of women and $24.6 \%$ of men, $p<0.001)$, moderate pain (5-7 points on the VAS scale) was felt by $48.5 \%$ of patients $(46.4 \%$ and $51.1 \%$ respectively, $p<0.05)$, whereas strong pain (8-10 points on the VAS scale) was felt by $31.3 \%$ of the respondents (36.7\% and $24.3 \%$ respectively, $p<0.001$ ). There was no difference in the incidence of mild, moderate, and severe pain with age, in both women and men.

\section{Pain intensity and pain location}

The highest intensity of pain was reported by study subjects with pain in the hips (6.5 points

Table V. Pain intensity measured by visual analog scale (VAS) in subjects with chronic pain in the PolSenior population

\begin{tabular}{|c|c|c|c|c|c|c|c|}
\hline \multirow{2}{*}{$\begin{array}{l}\text { Age group } \\
\text { [years] }\end{array}$} & \multicolumn{2}{|c|}{ Total } & \multicolumn{2}{|c|}{ Men } & \multicolumn{2}{|c|}{ Women } & \multirow[t]{2}{*}{$P$-value } \\
\hline & Mean & $\pm S D^{a}$ & Mean & $\pm S D^{a}$ & Mean & $\pm \mathrm{SD}^{\mathrm{a}}$ & \\
\hline $55-59$ & 6.0 & 2.0 & 5.8 & 2.1 & 6.2 & 1.9 & NS \\
\hline $65+$ & 6.2 & 2.1 & 5.9 & 2.0 & 6.5 & 2.1 & $<0.001$ \\
\hline $65-69$ & 6.1 & 2.1 & 5.9 & 2.0 & 6.3 & 2.1 & NS \\
\hline 70-74 & 6.3 & 2.1 & 5.8 & 1.9 & 6.7 & 2.1 & $<0.001$ \\
\hline $75-79$ & 6.3 & 2.0 & 5.8 & 2.0 & 6.6 & 2.0 & $<0.001$ \\
\hline $80-84$ & 6.4 & 2.1 & 6.0 & 2.1 & 6.7 & 2.0 & $<0.005$ \\
\hline $85-89$ & 6.1 & 2.1 & 5.7 & 1.9 & 6.4 & 2.1 & $<0.005$ \\
\hline 90 and over & 6.1 & 2.2 & 6.0 & 1.9 & 6.3 & 2.3 & NS \\
\hline
\end{tabular}

$S D^{a}$ - standard deviation. 
on the VAS scale), followed by pain in the knees (6.4 points), feet (6.4 points), neck (6.3 points), legs (6.3 points), lumbosacral region (6.2 points), hands (6.0 points) and upper back (6.0 points). The observed differences between the intensities of pain in different locations showed no statistically significant relationship. Analysis of variance showed a significant difference only between the intensity of pain in the hip as compared with shoulder pain $(p<0.005)$.

\section{Pain intensity and pain co-occurrence in multiple locations}

Self-assessment of pain intensity was analyzed in relation to the currently most painful site depending on the number of pain locations reported by the subjects (Figure 2). An increase in pain intensity with the number of pain sites was observed ( $p<0.001$, ANOVA). Average pain intensity increased significantly from 5.7 points in patients reporting pain in one place up to 7.2 points in those reporting six or more painful places.

\section{Pain and the use of health care}

People with pain aged 65 years and more compared to those without pain significantly more often reported seeking the advice of a family doctor a few times a month (54.6\% vs. $48.4 \%, p<0.001$ ). The proportion of people reporting seeking a health practitioner's advice only a few times a year was significantly higher among those reporting no pain compared with those with pain ( $48.4 \%$ vs. $43.6 \%$, $p<0.005)$. Contacting a family doctor less than once a year was observed in $3.2 \%$ of those not reporting pain and $1.8 \%$ of those with pain $(p<0.005)$.

\section{Discussion}

The results of studies on the prevalence of chronic pain in the elderly are quite divergent due to different criteria for chronic pain, pain intensity scales used, the populations studied (residents of their own homes, senior homes, long-term care institutions) or research methods (questionnaire and medical surveys, personal user surveys, telephone surveys or only on the basis of medical records and various registers). The nature of the PolSenior study was a survey conducted by a trained nurse at the respondent's place of residence.

Most projects describe groups of subjects in accordance with the age distribution in the population, resulting in a low proportion of respondents in the oldest age groups [20-22]. The PolSenior study used equally-numbered, 5-year age cohorts. The size of the studied cohorts allowed the assessment of trends due to age, with particular emphasis on the oldest age groups. The use of statistical weights for the population age

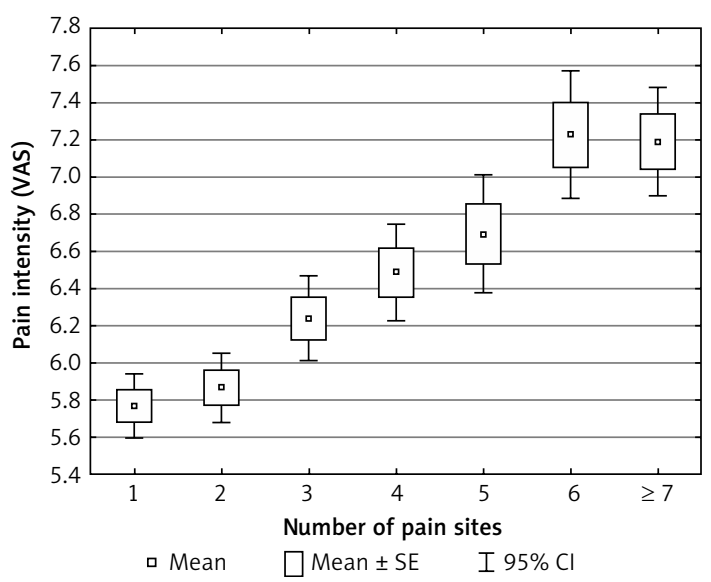

Figure 2. Relation of pain intensity to pain co-occurrence in multiple locations in subjects with chronic pain in the PolSenior population

structure helped to determine the prevalence of pain in Polish elderly. In the group surveyed within the PolSenior study, $42 \%$ of respondents aged 65 years and more reported chronic pain, which means that $43.8 \%$ of the elderly population of Poles suffers from chronic pain.

Similar prevalence of pain was found in the senior population of Spain (39.5\%) [16], Norway (32.5\%) [23], the United States (39.8\%) [17], and the United Kingdom (46\%) [24]. A higher prevalence of pain in elderly patients was observed in the population of Korea (60\%) [20], and lower in the Australian population (25.2\%) [15]. Extremely high incidence of pain (71.4\%) was found among the population of Catalonia [25]. Similar values (70-80\%) were observed among residents of senior homes and nursing homes in Poland [26]. It should be emphasized that in the PolSenior population, only $1 \%$ of respondents were institutionalized.

In the present study, chronic pain was more frequently reported in women than in men in each age group. The most frequent complaints of pain were reported by women aged 80-84 years (every second respondent) and men aged 65-69 years (four out of ten respondents) and, interestingly, least often by men and women aged 90 years and more (every third man and every fourth woman). In a Canadian study [27], the occurrence of pain increased in successive age groups and was greatest in nonagenarians $37.5 \%$ of the women and $28 \%$ of men). The prevalence of chronic musculoskeletal pain among British seniors attained a maximum (50\%) in the group aged 55-64 years, while in people aged $65-74$ years it was $42 \%$, and in people over 75 years it was $46 \%$ [24]. In the Australian study [28], as in the Polish study, the incidence of chronic pain was the most common in men aged 65-69 and women aged 80-84 years.

The topography of pain changes with age. Studies show that middle-aged people feel pain 
most frequently in the lumbosacral region, shoulders, upper limbs, and head, whereas in the elderly the pain resides dominantly in the lower limbs $[17,22,29]$.

In the PolSenior study, the incidence of low back pain was highest in the pre-elderly group (55-59 years $-60 \%)$ and lowest in those over 90 years (44.4\%). However, the occurrence of lower limb pain grew with age and was most frequent in 90-year-olds (53.5\%). In the Korean elderly population, back pain was more frequent (72.6\%) than pain of the lower extremities (59\%) [20].

In contrast, British [24] and Spanish [16] elderly subjects most frequently reported pain of the lower limbs. In the Finnish group of seniors aged 75 years and more, the most common site of pain was the lower limbs (40\%), reported almost twice as frequently as the lumbosacral region (21\%) [30].

It seems that the occurrence of headaches in the elderly is underestimated [31]. In the British study, it was observed that the prevalence of headaches was at a similar level in people between 18 and 54 years of age, and decreased to $5 \%$ in the oldest age group aged 75-101 years [24]. The Spanish study found that headaches were most common in those aged $18-29$ years (29\%) and least common in people over 65 years (7.5\%) [16]. In contrast, in the PolSenior study population, every fifth person aged 65-69 years and every third person aged 90 years and more suffered from headaches. Similarly, seniors in the Catalan population aged over 85 years experienced headaches more often than younger elderly (34.9\% vs. 32\%) [25]. The occurrence of head and neck pains may be a significant problem in the elderly, as they were reported by $33.3 \%$ and $54 \%$, respectively, of the Catalan population [25] as compared to $23.8 \%$ and $21 \%$, respectively, of the PolSenior study population.

The coexistence of many ailments is characteristic for the elderly. This also applies to feeling pains in different locations. In the PolSenior study, seven out of ten people with chronic pain reported pain in at least two locations (70.3\%), every second respondent in at least three places (47.9\%), onethird in at least four sites (33\%), and every fourth person in at least five locations (22.5\%). Almost every tenth person reported pain in at least seven locations. The greater the number of sites of pain reported, the greater was the predominance of women over men. Similarly, in the NorStOP study, older women compared to men were more likely to report the coexistence of pain in more than seven locations [22]. In a study of Korean seniors, pain in three or more locations was reported by $44 \%$ of women compared with $18 \%$ of men [20]. Nearly two-thirds $(63 \%)$ of people with chronic pain among adult residents of Olmsted County (USA) also reported multiple sites of pain [29].
Participants of the PolSenior study reported an average of 3.1 locations of chronic pain, and respondents of the Catalan study an average of 4.4 [25]. Among both the Polish and Catalan study population, the number of painful areas was significantly higher among women than men across the age spectrum.

There were no significant changes in pain intensity with age. Average pain intensity was quite high (6.2 points), every other person with chronic pain had moderate pain, and one-third had pain of high intensity. Mild to moderate pain was reported more frequently by men than women. The strongest pain was reported by those with pain of the hips, knees, and lumbosacral region, and the weakest in case of headaches. Higher pain intensity was reported by people who suffered from the co-occurrence of pain in several locations.

The study of pain intensity in the Finnish population aged over 75 years showed that $62 \%$ of respondents with chronic pain felt pain of a strong or moderate degree [30]. Similarly, high intensity of pain was reported by surveyed Canadian seniors: $55 \%$ of respondents with chronic pain felt moderate pain and $18 \%$ severe pain [32]. In a study of the Brazilian elderly, moderate pain was reported by $36 \%$ of respondents, with strong and very strong pain reported by as many as 34\% of respondents [18]. Among inhabitants of Danish residential homes, $85 \%$ reported pain intensity of 4 points or higher according to the Numerical Rating Scale (NRS) [33]. Most research shows that pain intensity is greater in people over 65 years of age than in younger ones, and higher in women than in men [34]. However, a recent study conducted in the Netherlands showed similar back pain intensity in age groups of 55-74 and 75 years and more [35].

In the PolSenior study, people with chronic pain significantly more often sought the advice of a family doctor than those without pain. The problem of pain in a family doctor's practice is very prevalent, but still underestimated [36]. Family doctors spend very little time identifying the problem of pain in the elderly [37]. Questions about the occurrence of pain, its location, intensity, and impact on daily functioning should therefore always be taken into account in interviews with older medical patients [38].

Future research including adequate representation of the oldest old, as in the PolSenior project, is needed, since it is the fastest growing segment of the older population.

In conclusion, the aging of the population is associated with high incidence of chronic pain, especially in women. Elderly people in Poland most frequently report pain of the lumbosacral region and lower limbs. Elderly people, especially women, 
are characterized by coexistence of pain in multiple locations. The intensity of pain increases with the number of pain sites. Elderly patients with chronic pain more often seek medical advice.

\section{Acknowledgments}

Implemented under publicly funded project entitled "Medical, psychological, sociological and economic aspects of aging in Poland" - PolSenior, no. PBZ-MEIN-9/2/2006, The Ministry of Science and Higher Education.

\section{Conflict of interest}

The authors declare no conflict of interest.

\section{References}

1. Ahacic K, Kareholt I. Prevalence of musculoskeletal pain in the general Swedish population from 1968 to 2002: age, period, and cohort patterns. Pain 2010; 151: 206-14.

2. Mossey JM, Gallagher RM, Tirumalasetti F. The effects of pain and depression on physical functioning in elderly residents of a continuing care retirement community. Pain Med 2000; 1: 340-50.

3. Oladeji BD, Makanjuola VA, Esan OB, Gureje O. Chronic pain conditions and depression in the Ibadan Study of Ageing. Int Psychogeriatr 2011; 23: 923-9.

4. Leveille SG, Jones RN, Kiely DK, et al. Chronic musculoskeletal pain and the occurrence of falls in an older population. JAMA 2009; 302: 2214-21.

5. Muszalik M, Kedziora-Kornatowska K, Kornatowski T. Functional assessment and health-related quality of life (HRQOL) of elderly patients on the basis of the functional assessment of chronic illness therapy (FACIT)-F questionnaire. Arch Gerontol Geriatr 2009; 49: 404-8.

6. Torvik K, Kaasa S, Kirkevold O, Rustoen T. Pain and quality of life among residents of Norwegian nursing homes. Pain Manag Nurs 2010; 11: 35-44.

7. Blyth FM, March LM, Brnabic AJ, Cousins MJ. Chronic pain and frequent use of health care. Pain 2004; 111: 51-8.

8. McLachlan AJ, Bath S, Naganathan V, et al. Clinical pharmacology of analgesic medicines in older people: im pact of frailty and cognitive impairment. Br J Clin Pharmacol 2011; 71: 351-64.

9. Shah RC, Buchman AS, Boyle PA, et al. Musculoskeletal pain is associated with incident mobility disability in community-dwelling elders. J Gerontol A Biol Sci Med Sci 2011; 66: 82-8.

10. Ordu Gokkaya NK, Gokce-Kutsal Y, Borman P, et al. Pain and quality of life (QoL) in elderly: the Turkish experience. Arch Gerontol Geriatr 2012; 55: 357-62.

11. Ozturk A, Simsek TT, Yumin ET, Sertel M, Yumin M. The relationship between physical, functional capacity and quality of life (QoL) among elderly people with a chronic disease. Arch Gerontol Geriatr 2011; 53: 278-83.

12. Reid KJ, Harker J, Bala MM, et al. Epidemiology of chronic non-cancer pain in Europe: narrative review of prevalence, pain treatments and pain impact. Curr Med Res Opin 2011; 27: 449-62.

13. Breivik H, Collett B, Ventafridda V, Cohen R, Gallacher D. Survey of chronic pain in Europe: prevalence, impact on daily life, and treatment. Eur J Pain 2006; 10: 287-333.
14. Langley PC. The prevalence, correlates and treatment of pain in the European Union. Curr Med Res Opin 2011; 27: 463-80.

15. Currow DC, Agar M, Plummer JL, Blyth FM, Abernethy AP. Chronic pain in South Australia - population levels that interfere extremely with activities of daily living. Aust N Z J Public Health 2010; 34: 232-9.

16. Catala E, Reig E, Artes M, Aliaga L, Lopez JS, Segu JL. Prevalence of pain in the Spanish population: telephone survey in 5000 homes. Eur J Pain 2002; 6: 133-40.

17. Johannes CB, Le TK, Zhou X, Johnston JA, Dworkin RH. The prevalence of chronic pain in United States adults: results of an Internet-based survey. J Pain 2010; 11: 1230-9.

18. Skare TL, Roesler E, Bataglin F. Chronic pain in older adults - a perspective from Brazil. Clinical Geriatrics 2010; 18(18)-september, www.consultant360.com/articles/chronic-pain-older-adults-perspective-brazil.

19. Bledowski P, Mossakowska M, Chudek J, et al. Medical, psychological and socioeconomic aspects of aging in Poland: assumptions and objectives of the PolSenior project. Exp Gerontol 2011; 46: 1003-9.

20. Baek SR, Lim JY, Park JH, et al. Prevalence of musculoskeletal pain in an elderly Korean population: results from the Korean Longitudinal Study on Health and Aging (KLoSHA). Arch Gerontol Geriatr 2010; 51: e46-51.

21. Kamaleri Y, Natvig B, Ihlebaek CM, Benth JS, Bruusgaard D. Number of pain sites is associated with demographic, lifestyle, and health-related factors in the general population. Eur J Pain 2008; 12: 742-8.

22. Thomas E, Peat G, Harris L, Wilkie R, Croft PR. The prevalence of pain and pain interference in a general population of older adults: cross-sectional findings from the North Staffordshire Osteoarthritis Project (NorStOP). Pain 2004; 110: 361-8.

23. Rustoen T, Wahl AK, Hanestad BR, Lerdal A, Paul S, Miaskowski C. Prevalence and characteristics of chronic pain in the general Norwegian population. Eur J Pain 2004; 8: 555-65.

24. Parsons S, Breen A, Foster NE, et al. Prevalence and comparative troublesomeness by age of musculoskeletal pain in different body locations. Fam Pract 2007; 24: 308-16.

25. Miro J, Paredes S, Rull M, et al. Pain in older adults: a prevalence study in the Mediterranean region of Catalonia. Eur J Pain 2007; 11: 83-92.

26. Zyczkowska J, Szczerbinska K, Jantzi MR, Hirdes JP. Pain among the oldest old in community and institutional settings. Pain 2007; 129: 167-76.

27. Meana M, Cho R, DesMeules M. Chronic pain: the extra burden on Canadian women. BMC Womens Health 2004; 4 Suppl 1: S17.

28. Blyth FM, March LM, Brnabic AJ, Jorm LR, Williamson M, Cousins MJ. Chronic pain in Australia: a prevalence study. Pain 2001; 89: 127-34.

29. Watkins EA, Phil D, Wollan PC, Melton LJ, Yawn BP. A population in pain: report from the Olmsted County health study. Pain Med 2008; 9: 166-74.

30. Karttunen N, Lihavainen K, Sipila S, Rantanen T, Sulkava R, Hartikainen S. Musculoskeletal pain and use of analgesics in relation to mobility limitation among community-dwelling persons aged 75 years and older. Eur J Pain 2012; 16: 140-9.

31. Thomas E, Boardman HF, Croft PR. Why do older people report fewer headaches? Gerontology 2005; 51: 322-8.

32. Ramage-Morin PL. Chronic pain in Canadian seniors. Health Rep (Statistics Canada, Catalogue 82-003) 2008; 19: 1-16. 
33. Boerlage AA, van Dijk M, Stronks DL, de Wit R, van der Rijt CC. Pain prevalence and characteristics in three Dutch residential homes. Eur J Pain 2008; 12: 910-6.

34. Chan A, Malhotra C, Do YK, Malhotra R, Ostbye T. Self reported pain severity among multiethnic older Singaporeans: does adjusting for reporting heterogeneity matter? Eur J Pain 2011; 15: 1094-9.

35. Scheele J, Enthoven WT, Bierma-Zeinstra SM, et al. Characteristics of older patients with back pain in general practice: BACE cohort study. Eur J Pain 2014; 18: 279-87.

36. Hasselstrom J, Liu-Palmgren J, Rasjo-Wraak G. Prevalence of pain in general practice. Eur J Pain 2002; 6 : 375-85.

37. Tai-Seale M, Bolin J, Bao X, Street R. Management of chronic pain among older patients: inside primary care in the US. Eur J Pain 2011; 15: 1087.e1-8.

38. Weiner DK, Turner GH, Hennon JG, Perera S, Hartmann $\mathrm{S}$. The state of chronic pain education in geriatric medicine fellowship training programs: results of a national survey. J Am Geriatr Soc 2005; 53: 1798-805. 